Article

\title{
Key Technologies and Development Trends of 5G Optical Networks
}

\author{
Shu-Hao Chang (1) \\ Science and Technology Policy Research and Information Center, National Applied Research Laboratories, \\ Taipei 10636, Taiwan; shchang@narlabs.org.tw
}

Received: 23 September 2019; Accepted: 8 November 2019; Published: 12 November 2019

Featured Application: In this study, the researchers explore the technology development trends in 5G optical networks, and the results may serve as a reference for the government in observing emerging technologies.

\begin{abstract}
With the development of 5G, 5G optical networks have gradually received increasing attention from scholars. However, most studies have focused on discussing the technical or market aspect. Furthermore, their findings have not provided a panorama of the technologies in the 5G domain, nor have they provided a detailed understanding of the key technologies and development trends. An optical network is an indispensable type of infrastructure for the development of 5G. Therefore, defining key technologies in this domain is particularly crucial. The present study used patents for $5 \mathrm{G}$ optical networks as the basis of its analysis and constructed a technology network using a network analysis method. Research results indicated that the key technologies provided by 5G optical networks include wireless communication network facilities and local resource management (H04W88 and H04W72), selection arrangements for multiplex systems (H04Q11), and arrangements enabling multiple uses of the transmission path (H04L5). The maturation of optical component technology has paved the way for multiplex communication system technology to flourish and made it one of the key technologies in the development of 5G. Additionally, an analysis of top patentees revealed that information technology companies are the main force in developing $5 \mathrm{G}$ optical network technologies. Thus, driven by the market, $5 \mathrm{G}$ optical communication has become the technical focus of the private sector. In this study, the researchers constructed a technology network model to explore the technology development trends, and the results may serve as a reference for the government in observing emerging technologies.
\end{abstract}

Keywords: optical network; fifth-generation mobile communication system; patent analysis; technology evolution; network analysis

\section{Introduction}

Internet backend users' demand for high bandwidth services, such as high quality images, high-speed and high-capacity data transmission, mobile broadband, big data, the Internet of Things (IoT), and cloud services, has been increasing rapidly. Transmission mediums based on coaxial cables and twisted pairs, including power-line communication, asymmetric digital subscriber line, and very-high-bitrate digital subscriber line, are no longer sufficient for supporting the high bandwidth services demanded by users. Because coaxial cables have a limited data-carrying capacity, with a maximum downstream capacity of only $200 \mathrm{Mbit} / \mathrm{s}$, they cannot satisfy users' demand for bandwidth capacity. This renders optical networks crucial, and indeed, such networks have been receiving considerable academic attention from scholars [1-3]. 
Regarding the development of $5 \mathrm{G}$ and optical networks, $5 \mathrm{G}$ is a next-generation product in the domain of personal mobile communication; it will ultimately replace the $4 \mathrm{G}$ system currently in use. The key characteristics of 5G are a higher capacity and lower latency, which could support a higher density of mobile users as well as provide a comprehensive infrastructure for IoT and machine-to-machine (M2M) communication. According to a study conducted by Research and Markets, 5G will create considerable new opportunities for the optical networking industry through the 5G infrastructure- both backhaul and fronthaul [4]. In response to the transmission requirements for 5G (i.e., low latency, high transmission volume, and the transmission of big data), network infrastructures must be enhanced through upgrading optical networks. Accordingly, the United Kingdom published the Future Telecoms Infrastructure Review, in which it stated that the country aims to connect 15 million premises to full fiber broadband by 2025 and ultimately achieve the target of nationwide fiber broadband coverage [5]. The development of 5G requires more optical resources. For example, the radio access network (RAN) architecture for mobile $5 \mathrm{G}$ and beyond is undergoing a fundamental evolution, bringing optics into the world of radio [6]. Using optical networks could increase transmission distances and data bandwidths, while simultaneously reducing energy consumption. Optical fiber is a pathway that is thinner than human hair and can be used to transmit light. By contrast, metal wires are more maintenance-intensive and prone to signal degradation and electromagnetic interference. The use of optical fiber substantially increases the data transmission capacity. An optical fiber can achieve a bandwidth that requires several thousand copper wires, which is why most submarine and transcontinental communication cables are made of optical fiber. Therefore, optical fiber remains one of the most favorable options for data transmission. The high bandwidth and transmission volume of high-speed optical networks fulfill the requirements of device-to-device (D2D) transmission. Additionally, it could minimize paralysis and disconnections on 5G networks, enable the serial connection of more devices, and enable direct communication between devices-beyond interactions between people and devices.

To date, studies have held preliminary discussions on the topic of $5 \mathrm{G}$ optical networks [4,6-9]; however, such studies have mostly focused on discussions on the technical [6-8] or the market aspects $[4,9]$. Furthermore, their findings have not indicated the key development domains for 5G optical networks. The development of 5G could create considerable business opportunities [10], and optical networks are an indispensable type of infrastructure for the development of 5G; therefore, the incorporation of wireless and optical communication into access networks is an inevitable future development trend. Additionally, patents are the manifestation of industrialized technologies; they are beneficial for businesses to achieve monopoly in the technology market, and could serve as indicators for technology development trends [11-13]. Therefore, in the current study, the researchers identified key technologies and development trends in 5G optical networks by analyzing the patent data and using a network analysis method.

Overall, the current study differs from most relevant studies, which focused on discussions at the technical or market level. The current study examines the technology deployment and landscape of $5 \mathrm{G}$ optical networks from a macro perspective. Furthermore, the researchers focus on constructing a technology network model and identifying technology development trends. They hope that this study's results can serve as a reference for the government, academia, and industry.

\section{Literature Review}

\subsection{Development of 5 G Optical Networks}

The age of $5 \mathrm{G}$ is also the age of the Internet of Everything. The successful realization of concepts such as the IoT and artificial intelligence is dependent on the establishment of a comprehensive 5G network system. Currently, much of the traditional public network is already "fiberized" [9]. In other words, the development of 5G will deeply affect and change the development patterns and pace of the optical communication industry. To adapt to new technical and application requirements 
generated by $5 \mathrm{G}$, the technology and standards of the new generation of information communication technology (e.g., optical transport and optical access networks), the establishment and deployment of such networks, as well as the use of new optical devices and modules, will be essential.

Additionally, because of characteristics inherent to the age of 5G (e.g., the mobility of users' devices, real-time data transmission, and bandwidth requirements of big data), network control methods in the age of $5 \mathrm{G}$ require a higher level of ultrareliable and low-latency communications compared with conventional network control methods. This places an incredibly high demand on the transmission and processing of wireless communication in 5G fronthaul networks. The adaptation, transmission, and exchange of wireless communication in optical networks must be completed in an extremely short time, which constitutes a great challenge faced by $5 \mathrm{G}$ fronthaul optical networks [6]. Therefore, some optical communication discussions have been initiated to solve the bandwidth and latency problems faced by future 5G networks. Solutions that have been proposed include a dense wavelength-division-multiplexed passive optical network [14], orthogonal frequency division multiplexing [15,16], and space division multiplexing [17]. Future 5G optical network operators should work toward establishing the large bandwidth and low latency required for the efficient transmission of user data. Furthermore, a key goal of a $5 \mathrm{G}$ optical network is to achieve the efficient transmission of big data through the use of the multidimensional (i.e., time, wavelength, and space dimensions) multiplexing technology of optical networks.

Today, technical investments in 5G optical networks are constantly growing. In Europe alone, 5G will generate US\$363-606 billion in growth for network equipment manufacturers, and comparable investment can be expected in North America and Asia. Creating optical backhaul and fronthaul networks for 5G may represent the largest opportunity for optical equipment and cable manufacturers [9]. Given the considerable potential business opportunities 5G and IoT technologies could engender, governments worldwide are actively facilitating technology development and establishing related infrastructure [18]. The topic of incorporating optical network technologies into the development and application of 5G has sparked the attention of both academia and industry [6-9]. For example, an Institute of Electrical and Electronics Engineers (IEEE) working group on Time-Sensitive Networking (TSN) included the application of optical networks in its research agenda [19]. Given the development potential of 5G optical networks, an in-depth observation of technologies in this domain is imperative. Because $5 \mathrm{G}$ optical networks exhibit diverse future applications, and patents are the concrete outputs of industrialized technologies, the researchers conducted a patent analysis, with a focus on 5G optical networks, to identify the key technologies and development trends of 5G optical networks, and employed the network analysis method to explore identified key technologies. This network analysis method is explained further in the following subsection.

\subsection{Technology Network Analysis}

In recent years, studies have used a network analysis method to explore the flow or development pathways of knowledge [20-22] and identified the evolution patterns and possible development directions of technical knowledge [23,24]. Additionally, some studies have conducted a patent analysis to examine the status or performance of technical collaborations [25-27]. A network analysis can accurately display the communication paths of information, as well as the scope of knowledge domains. Specifically, analyzing patent data can provide objective and feasible information, and the data include the number of patents, year of approval, and technology category [28]. Therefore, a patent analysis is a useful approach to analyzing the development of a specific technology. Patents are sources of technical knowledge, and a network analysis could reveal the interdependence and embeddedness of various technologies. In short, network analysis is a useful tool for observing research and development activities [29-31]. Thus, in the current study, the researchers used a network analysis method to examine the connectivity and cooccurrence of technology nodes to identify the key players of $5 \mathrm{G}$ optical networks, as well as to observe and gain an enhanced understanding of the key domains and technology development trends of 5G optical networks. 


\section{Research Design}

\subsection{Search Strategies and Data Sources}

For the patent analysis, the researchers sourced data from the database of the United States Patent and Trademark Office (USPTO). The main reason for this selection was the fact that it is a rich database with the earliest data traced back to 1975. Additionally, because the US is the world's largest commercial trading market, most inventors apply for patents for their products in the US while simultaneously doing so in other countries. Therefore, when researchers measure innovative activities and innovative performance at the global level, they typically use data from the USPTO database [21,32]. For the present study, the patent data consisted of US patents approved between 1 January 2014 and 30 June 2019. Additionally, the researchers used a more precise search method-Derwent Smart Search-to conduct the patent search. Smart Search is a search tool developed by hundreds of experts, who first completed the reading of official patent disclosures in the database. Subsequently, procedures such as translation, abstract rewriting, content debugging, and patentee information normalization were performed. Lastly, the modified and normalized data were stored in the database. In short, Smart Search is a keyword search tool established through reading and organization by people. The search criteria of the current study were as follows: (SSTO/5th-Generation) and (SSTO/optical network); a total of 124 patents were retrieved. In terms of technology classification, the Cooperative Patent Classification (CPC) system has been implemented since early 2013. Therefore, the researchers adopted the CPC system as their analytical framework. Considering that a patent may involve multiple CPC technologies and that individual patents may overlap in certain CPC technology fields, the more frequently a set of different CPC technologies is applied in a same patent, the higher the level of technological interrelatedness between them. Therefore, as when determining the relationships between members of a social network, the relationship between CPC technologies (nodes) and their application frequency (sides) in a same patent can be used for the construction of a technology network. A node, or player, situated at the center of a technology network is a key player, or key technology [33].

\subsection{Centrality Analysis for the Technology Network}

The key players of a network can be identified using the network-centric analytic approach [30]; the players located at the center of the network have a higher level of influence compared with the other players in the network [31]. Several studies have conducted a centrality analysis to either determine the knowledge map and hotspots of a specific domain [34,35] or identify the broker and gatekeeper in a technical collaboration network [36,37]. In view of the effectiveness of centrality analysis in determining whether a player is key, most studies have adopted a network-centric analytic approach for the identification of key players [38], considering that players at the center of a network have a greater influence on other players [39]. Table 1 lists the formulas for calculating the centrality of each technology domain.

First, closeness centrality refers to the reciprocal of sum of the length of the shortest paths between a certain node and others; the closer a node is to others, the more accessible or approachable it is. Next, betweenness centrality is the extent to which a node serves as an intermediary (or mediator) node which certain nodes depend on to connect with other nodes in a network; it measures the importance of a node in information transmission. Lastly, fragmentation centrality measures the proportion of nodes that cannot connect with each other after a certain node is removed. A small value indicates that the network remains stable after the node is removed, implying that the node has a low level of importance in the network. With reference to Borgatti [31], the researchers used distance-weighted fragmentation to measure fragmentation centrality. 
Table 1. Methods used for measuring the centrality of the technology network.

\begin{tabular}{cl}
\hline \multicolumn{1}{c}{ Indicator } & \multicolumn{1}{c}{ Formula } \\
\hline Closeness centrality & $\mathrm{C}_{c}(i)=\left[\sum_{j=1}^{n} d(i, j)\right]^{-1}$ \\
& $d(i, j)$ represents the distance from node $i$ to node $j$. \\
\hline & $C_{b}(i)=\sum_{i \neq j \neq k}^{n} d_{j k}(i) / d_{j k}$ \\
Betweenness centrality & $\begin{array}{l}d_{j k} \text { represents the number of shortest paths from node } j \text { to node } k ; d_{j k}(i) \\
\text { represents the number of shortest paths that must pass through node } i \text { to } \\
\text { get from node } j \text { to node } k .\end{array}$ \\
\hline Fragmentation centrality & $\begin{array}{l}C_{f}(i)=1-\frac{2 \sum_{i>j} \frac{1}{d(i, j)}}{n(n-1)} \\
d(i, j) \text { represents the distance from node } i \text { to node } j . \\
n \text { represents the total number of nodes. }\end{array}$ \\
\hline
\end{tabular}

\section{Empirical Study}

\subsection{Overview of 5 G Optical Networks}

Before the researchers performed the technology network analysis, they first analyzed the patent search results to obtain a preliminary understanding of the status of technology development. A complete CPC code consists of five levels, namely the Section, Class, Subclass, Main group, and Subgroup (e.g., H04Q 11/00). Table 2 lists the top 10 level-4 CPC codes of 5G optical networks with regards to their frequency of appearance.

Table 2. Frequency distribution of the top 10 level-4 CPC (Cooperative Patent Classification) codes.

\begin{tabular}{cccc}
\hline Ranking & CPC Code & Frequency of Appearance & Percentage \\
\hline 1 & H04B10 & 146 & $10.38 \%$ \\
2 & H04W88 & 92 & $6.54 \%$ \\
3 & H04B7 & 76 & $5.40 \%$ \\
4 & H04L5 & 75 & $5.33 \%$ \\
5 & H04J14 & 68 & $4.83 \%$ \\
6 & H04Q11 & 66 & $4.69 \%$ \\
7 & H04W72 & 66 & $4.69 \%$ \\
8 & H04L27 & 62 & $4.48 \%$ \\
9 & H04W84 & 43 & $4.41 \%$ \\
10 & H04L25 & & $3.06 \%$ \\
\hline
\end{tabular}

In terms of CPC distribution, the results encompassed a total of $104 \mathrm{CPC}$ technologies. Table 2 indicates that the focus of 5G optical network technologies is mostly on H04B10, H04W88, H04B7, H04L5, and H04J14; Appendix A displays the definition of each CPC code. According to the CPC definition, H04B10 belongs to transmission systems employing electromagnetic waves other than radio waves, such as infrared, visible, or ultraviolet light, or those employing corpuscular radiation, such as quantum communication; H04W88 belongs to devices specially adapted for wireless communication networks, such as terminals, base stations, or access point devices; H04B7 belongs to radio transmission systems, such as those using radiation fields; H04L5 belongs to arrangements affording multiple uses of the transmission path, as well as the presentation of data, record carriers, and handling record carrier; and lastly, H04J14 belongs to optical multiplex systems.

The analysis results indicated that the focuses of 5G optical networks lie in the following domains: radio transmission systems employing electromagnetic waves other than radio waves; wireless communication network facilities; the transmission of digital information; and optical multiplex systems. Additionally, the researchers conducted analysis of the top 10 patentees (Table 3). The results 
revealed the patentee with the highest number of approved patents in recent years to be Huawei Technologies Co., Ltd., followed by Smart Mobile, Inc., and Telefonaktiebolaget LM Ericsson (publ). Among the top patentees, Telefonaktiebolaget LM Ericsson (publ) has been actively promoting the development of 5G. The company published a report titled 5G Business Potential to uncover the unexplored potential business opportunities for telecommunication operators under the current trend of industry digitization, prompting these operators to deliberate over their company values and business model as a network developer, service facilitator, and service creator to gain a head start in the industry.

Table 3. Number of approved patents of the top 10 patentees.

\begin{tabular}{ccccc}
\hline Ranking & Patentee & $\begin{array}{c}\text { Number of } \\
\text { Patents }\end{array}$ & $\begin{array}{c}\text { Percentage } \\
\text { Average Age } \\
\text { of Patents }\end{array}$ \\
\hline 1 & Huawei Technologies CO., LTD. & 11 & $8.87 \%$ & 1 \\
2 & Smart Mobile INC. & 8 & $6.45 \%$ & 4 \\
3 & Telefonaktiebolaget LM Ericsson (publ) & 7 & $5.65 \%$ & 1 \\
4 & AT\&T Intellectual Property I, L.P. & 6 & $4.84 \%$ & 2 \\
5 & Inphi Corporation & 6 & $4.84 \%$ & 2 \\
6 & Dali Research (Northwind) LLC & 6 & $4.84 \%$ & 3 \\
7 & Futurewei Technologies INC. & 5 & $4.03 \%$ & 2 \\
8 & Corning Optical Communications LLC & 5 & $4.03 \%$ & 2 \\
9 & Google LLC & 3 & $2.42 \%$ & 2 \\
10 & Nippon Telegraph and Telephone Corporation & 3 & $2.42 \%$ & 2 \\
\hline
\end{tabular}

\subsection{Key Technology Network Analysis}

For identifying key technologies, the researchers used patent data from the CPC system for analysis. The centrality of a node was determined by its closeness centrality, betweenness centrality, and fragmentation centrality. All three are effective indicators of centrality. Borgatti [31] used the concepts of key player problem-positive and key player problem-negative to define key players in a network. Key player problem-positive refers to a certain node's connectivity to other nodes compared with that of its peers. It is primarily determined by the node's closeness centrality. Key player problem-negative designates a certain node's role in maintaining network stability, that is, the likelihood of network fragmentation once that node is removed. Key player problem-negative is primarily determined by betweenness centrality and fragmentation centrality. The network model of the key technologies is presented in Figure 1, and the key CPCs are presented in Table 4.

Table 4. Top five CPC codes of 5G optical networks.

\begin{tabular}{cccccc}
\hline CPC & $\begin{array}{c}\text { Closeness } \\
\text { Centrality }\end{array}$ & CPC & $\begin{array}{c}\text { Betweenness } \\
\text { Centrality }\end{array}$ & CPC & $\begin{array}{c}\text { Fragmentation } \\
\text { Centrality }\end{array}$ \\
\hline H04W88 & 90 & H04W88 & 696.273 & H04W88 & 0.470 \\
H04W72 & 80 & H04B10 & 470.019 & H04B10 & 0.468 \\
H04Q11 & 78.5 & H04L5 & 367.544 & H04L5 & 0.467 \\
H04W84 & 77.5 & H04W72 & 297.066 & H04Q11 & 0.466 \\
H04L5 & 77 & H04Q11 & 286.362 & H04W72 & 0.465 \\
\hline
\end{tabular}




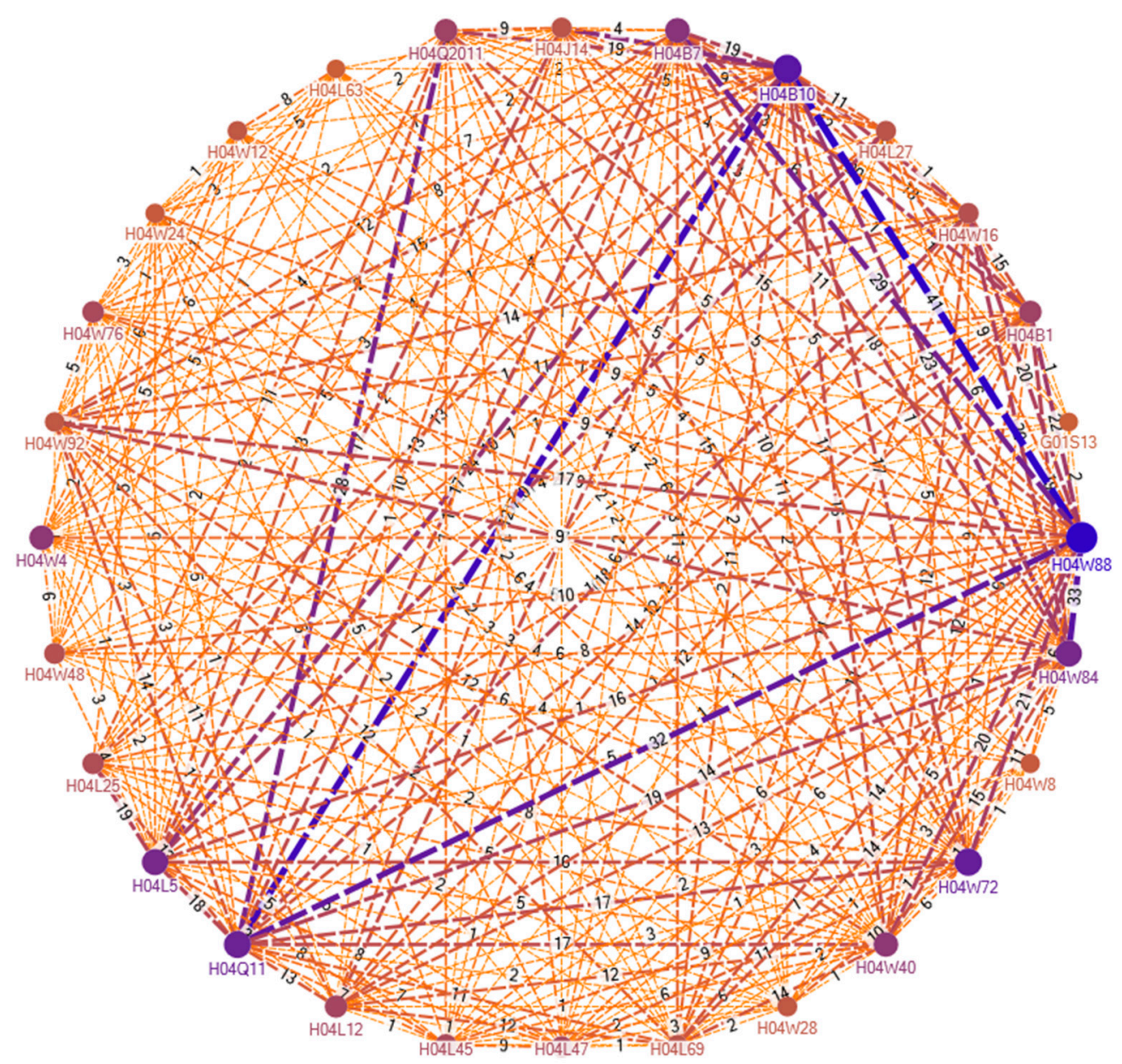

Figure 1. Level-4 CPC network of 5G optical networks. Note: The size of a node indicates the number of nodes it is connected to. The thickness of an arc indicates the strength of the connection, namely the number of patents shared. To keep the figure succinct, only nodes that were connected to more than 25 other nodes were retained.

Table 4 shows that H04W88, H04W72, H04Q11, and H04L5 are the top five technology domains in $5 \mathrm{G}$, as indicated by their closeness, betweenness, and fragmentation centrality. These results suggest that the key technologies for $5 \mathrm{G}$ optical networks mostly lie in the domains of wireless communication network facilities and local resource management (H04W88 and H04W72), selecting arrangements for multiplex systems (H04Q11), and arrangements affording multiple uses of the transmission path (H04L5). Accordingly, the most critical 5G optical network technologies are those related to wireless communication network facilities and multiplex communication systems. In particular, the advancement of optical component technology (e.g., semiconductor lasers, optical amplifiers, and optical filters) paved the way for the flourishing of multiplex communication system technology, which enabled the provision of diversified and high-capacity broadband services. The development of these relevant technologies should dominate the development trends of 5G optical networks in the future.

\subsection{Technical and Development Trends of 5 G Optical Networks}

To present the technical development trajectory of $5 \mathrm{G}$ optical networks, the researchers examined the changes in the focus of research and development over the years by using the technology networks of different stages. Using 2016 as a cutoff point, they segmented the time period into an early and a later stage. The development trends of each technology were illustrated using the increase or decrease in centrality of its CPC codes. Table 5 displays the results: 
Table 5. Key trends in technical developments for 5G optical networks.

\begin{tabular}{ccccc}
\hline $\begin{array}{c}\text { Centrality } \\
\text { Indicators }\end{array}$ & $\begin{array}{c}\text { Focuses in the } \\
\text { Early Stage }\end{array}$ & $\begin{array}{c}\text { Focuses in the } \\
\text { Later Stage }\end{array}$ & $\begin{array}{c}\text { New Technology } \\
\text { Domains }\end{array}$ & $\begin{array}{c}\text { Eliminated } \\
\text { Technology } \\
\text { Domains }\end{array}$ \\
\hline $\begin{array}{c}\text { Closeness } \\
\text { centrality }\end{array}$ & $\begin{array}{c}\text { H04W88, H04W84, } \\
\text { H04W72, H04W40, } \\
\text { H04Q11 }\end{array}$ & $\begin{array}{c}\text { H04W88, H04B10, } \\
\text { H04Q11, H04L5, } \\
\text { H04W72 }\end{array}$ & H04B10, H04L5 & H04W84, H04W40 \\
Betweenness \\
centrality & $\begin{array}{c}\text { H04W88, H04B10, } \\
\text { H04W84, H04W72, } \\
\text { H04W12 }\end{array}$ & $\begin{array}{c}\text { H04W88, H04B10, } \\
\text { H04Q11, H04L5, } \\
\text { H04W84 }\end{array}$ & H04Q11, H04L5 & H04W72, H04W12 \\
Fragmentation \\
centrality
\end{tabular}

Note: 49 patents with 80 CPC codes were observed in the early stage (2014-2016).

Table 5 indicates that among the patents approved prior to 2008, H04W12 (security arrangements), H04W84 (network topologies), as well as H04W40 and H04W72 (communication routing and allocation of wireless resources) surpassed the other technology domains in terms of their closeness, betweenness, and fragmentation centrality; this differs from the technological focuses of the later stage, which consisted of H04B10 (transmission systems employing electromagnetic waves other than radio waves), as well as H04L5 and H04Q11 (multiplex communication systems). Both H04L5 and H04Q11 technology nodes have been recognized as having high betweenness centrality and fragmentation centrality in terms of key player problem-negative. This indicates that they both play a bridging and critical role in connecting technology clusters within 5G optical networks.

\section{Conclusions}

\subsection{Discussion}

In the current study, the researchers used a network analysis method to explore the key technologies of 5G optical networks. The empirical results revealed that the focuses of such technologies are mostly on wireless communication network facilities and multiplex communication systems. The maturation of optical component technology paved the way for multiplex communication system technology to flourish, and made it one of the key technologies in the development of 5G. Additionally, an analysis of the top patentees revealed that information technology companies such as Huawei Technologies Co., Ltd. and Telefonaktiebolaget LM Ericsson (publ) hold a relatively high number of patents; this indicates that information technology companies in the private sector are the main force in developing $5 \mathrm{G}$ optical network technologies compared with universities and the public sector, which implies the potential of 5G optical networks in future market development. As stated in the 5G Business Potential report, $5 \mathrm{G}$ has the potential to generate high revenue for agencies worldwide [40]. Furthermore, driven by the market, $5 \mathrm{G}$ optical communication has become the technical focus of the private sector.

In terms of technical trends over the years, the researchers found that key technologies in 5G optical networks have shifted from network topologies and security arrangements to transmission systems employing electromagnetic waves other than radio waves, as well as multiplex communication systems. In particular, multiplex communication systems have become one of the pillar technologies in the development of $5 \mathrm{G}$ optical networks. In this age of 5G, the volume of digital data being transmitted has increased exponentially. The purpose of multiplex systems is to make $5 \mathrm{G}$ available to all people without them interfering with each other. In short, multiplex systems could increase data rate and fulfill the needs of each user or object. For example, the key technology of dense wavelength-division-multiplexed passive optical network (DWDM-PON) is the provision of different wavelengths to the optical network units connecting to a central office, which facilitates the simultaneous transmission of multiple users. It also reduces the number of optical fibers that have to be deployed by enabling the sharing of existing 
optical network infrastructures. As a result, considerable network construction and maintenance costs are saved. The innovative integration of DWDM-PON and millimeter-wave wireless transmission will become mainstream in the foreseeable future, given that they enhance user data rate, end-to-end connectivity, connection density, and traffic volume density at a reduced cost. Such a development trend is similar to the predictions made by other scholars [14,41]. In conclusion, the results of the current study correspond with the development trends of this emerging domain.

Relevant studies on 5G optical networks have predominantly focused on discussions on the technical [6-8] or market aspects [4,9]; however, their findings have not provided a detailed understanding of the key technologies and technical development trends in 5G optical networks. In particular, the indispensability of optical networks to the development of $5 \mathrm{G}$ renders observations on the distribution of optical network technologies crucial. Presenting the whole picture of 5G optical network technologies, the current study filled this research gap by revealing the key technologies and development trends in $5 \mathrm{G}$ optical networks using a technology network analysis.

In terms of policy suggestions, the technology map of 5G optical networks could provide valuable insights for the government. This technology network of 5G optical networks revealed the technical development focuses, which provided the government with relevant information, particularly that related to the shifts in key technology domains in recent years. The findings of the current study indicate that multiplex communication systems have become the key technology. With the ever-increasing demand for communications between people and objects as well as between objects, multiplex communication systems will play an increasingly crucial role in coming years. Therefore, the government should engage domestic hardware and software service providers in developing comprehensive solutions in response to the development trends of the optical communication industry to develop technologies that match market demands.

\subsection{Limitations and Future Research Directions}

First, the current study only used patent data as the basis for analyzing technology development trends. However, the output of the development of 5G optical networks is not limited to registered patent data; its output is also presented in other forms, such as journal articles, conference papers, exchanges between talents, and trade fairs. This study did not include other forms of outputs, which is a major limitation of this research. Second, the researchers used the patent keywords compiled in the Derwent database as the basis for filtering patent data. Despite the Derwent database having been established through a complete reading of official patent disclosures by hundreds of experts and compiled through human reading, the domain of 5G optical networks changes rapidly with each passing day. Certain patents from rapidly developing technology domains may contain technologies that belong to the scope of 5G optical networks; however, such data were not included in the current study's analysis. Thus, future researchers are advised to expand their analysis scope by incorporating expert interviews and other research designs that could aid the incorporation of more relevant patent data. Third, this study relied solely on the USPTO database, the world's largest database for commercial transactions, for its patent information. Therefore, although this database is highly representative and has a long history of use [21,32], researchers of future studies are advised to expand their sources of data by including other patent agencies, if time and budget allow it. The Worldwide Patent Statistical Database (PATSTAT) managed by the European Patent Office, for example, can be a suitable addition to increase the width of research scope. Fourth, future research may include the high-impact peer-reviewed journal sources within a reasonable technology readiness level period of the reported patents to increase research contributions. Finally, because of time constraints and macro-level examination of the technology network of $5 \mathrm{G}$ optical networks, the researchers only used the number of patents as the basis for their empirical examination and failed to further analyze the content of each individual patent. Therefore, to obtain a more accurate observation of technology trends in line with market needs, future studies should analyze the content of individual patents. 
Funding: This research was funded by the Ministry of Science and Technology of the Taiwan, grant number MOST 108-2410-H-492-001.

Acknowledgments: The authors would like to thank the Ministry of Science and Technology of the Taiwan for financially supporting this research under Contract No. MOST 108-2410-H-492-001.

Conflicts of Interest: The authors declare no conflict of interest.

\section{Appendix A}

Table A1. Definitions of the level-4 CPC categories.

\begin{tabular}{|c|c|}
\hline CPC Categories & Meaning \\
\hline H04B7 & Radio transmission systems, i.e., using radiation field \\
\hline H04B10 & $\begin{array}{c}\text { Transmission systems employing electromagnetic waves other than radio-waves, e.g., } \\
\text { infrared, visible or ultraviolet light, or employing corpuscular radiation, e.g., } \\
\text { quantum communication }\end{array}$ \\
\hline H04J14 & Optical multiplex systems \\
\hline H04L5 & Arrangements affording multiple use of the transmission path \\
\hline H04L25 & Baseband systems \\
\hline H04L27 & Modulated-carrier systems \\
\hline H04Q11 & Selecting arrangements for multiplex systems \\
\hline H04W12 & $\begin{array}{l}\text { Security arrangements, e.g., access security or fraud detection; authentication, e.g., } \\
\text { verifying user identity or authorization; protecting privacy or anonymity }\end{array}$ \\
\hline H04W40 & Communication routing or communication path finding \\
\hline H04W72 & $\begin{array}{c}\text { Local resource management, e.g., wireless traffic scheduling or selection or allocation of } \\
\text { wireless resources }\end{array}$ \\
\hline H04W80 & Wireless network protocols or protocol adaptations to wireless operation \\
\hline H04W84 & Network topologies \\
\hline H04W88 & $\begin{array}{l}\text { Devices specially adapted for wireless communication networks, e.g., terminals, base } \\
\text { stations or access point devices }\end{array}$ \\
\hline
\end{tabular}

\section{References}

1. Horvath, T.; Munster, P.; Dubravec, L.; Filka, M. Novel rogue optical network unit detection algorithm for gigabit passive optical networks. Opt. Appl. 2016, 46, 421-433.

2. Sarigiannidis, P.; Kakali, V.; Fragakis, M. An adaptive energy-efficient framework for time-constrained optical backbone networks. Int. J. Commun. Syst. 2017, 30,1-26. [CrossRef]

3. Shao, Q.; Gan, C.; Wang, R. Extensible optical access network enabling multistage protections and data aggregation based on tangent rings. Int. J. Commun. Syst. 2014, 27, 2775-2784. [CrossRef]

4. ResearchAndMarkets. Optical Networking Opportunities in 5G Wireless Networks: 2017-2026; ResearchAndMarkets: Dublin, Ireland, 2017.

5. Wright, J. Future Telecoms Infrastructure Review; Department for Digital, Culture, Media \& Sport: London, UK, 2018.

6. Zhang, J.; Ji, Y.; Yu, H.; Huang, X.; Li, H. Experimental demonstration of fronthaul flexibility for enhanced CoMP service in $5 \mathrm{G}$ radio and optical access networks. Opt. Express 2017, 25, 21247-21258. [CrossRef] [PubMed]

7. Zhao, Y.; Chen, Z.; Zhang, J.; Wang, X. Dynamic optical resource allocation for mobile core networks with software defined elastic optical networking. Opt. Express 2016, 24, 16659-16673. [CrossRef] [PubMed]

8. Yang, H.; He, Y.; Zhang, J.; Ji, Y.; Bai, W.; Lee, Y. Performance evaluation of multi-stratum resources optimization with network functions virtualization for cloud-based radio over optical fiber networks. Opt. Express 2016, 24, 8666-8678. [CrossRef] [PubMed]

9. Communications Industry Researchers. Optical Networking Opportunities in the 5G Infrastructure Market: 2019 to 2028; Communications Industry Researchers: Crozet, VA, USA, 2019. 
10. ResearchAndMarkets. 5G Infrastructure Market; ResearchAndMarkets: Dublin, Ireland, 2019.

11. Gwak, J.H.; Sohn, S.Y. Identifying the trends in wound-healing patents for successful investment strategies. PLoS ONE 2017, 12, e0174203. [CrossRef] [PubMed]

12. Kwon, S.; Lee, J.; Lee, S. International trends in technological progress: Evidence from patent citations, 1980-2011. Econ. J. 2017, 127, 50-70. [CrossRef] [PubMed]

13. Noh, H.; Song, Y.K.; Lee, S. Identifying emerging core technologies for the future: Case study of patents published by leading telecommunication organizations. Telecommun. Policy 2016, 40, 956-970. [CrossRef]

14. Zhang, Z.; Jiang, X.; Wang, J.; Chen, X.; Wang, L. Bidirectional $10 \mathrm{~Gb} / \mathrm{s} / \lambda$, channel-reuse, long-reach DWDM-PON employing tunable optical transceiver with optical intensity detection-based wavelength management. Opt. Quantum Electron. 2015, 47, 2767-2779. [CrossRef]

15. Geng, Z.; Kong, D.; Corcoran, B.; Guan, P.; Da Ros, F.; Porto da Silva, E.; Oxenløwe, L.K.; Lowery, A.J. All-optical OFDM demultiplexing with optical partial fourier transform and coherent sampling. Opt. Lett. 2019, 44, 443-446. [CrossRef] [PubMed]

16. Mandalawi, Y.N.A.; Yaakob, S.; Adnan, W.A.W.; Yaacob, M.H.; Zan, Z. Laser phase noise effect and reduction in self-homodyne optical OFDM transmission system. Opt. Lett. 2019, 44, 307-310. [CrossRef] [PubMed]

17. Cai, C.; Sun, Y.; Zhang, Y.; Zhang, P.; Niu, J.; Ji, Y. Experimental wavelength-space division multiplexing of quantum key distribution with classical optical communication over multicore fiber. Opt. Express 2019, 27, 5125-5135. [CrossRef] [PubMed]

18. CTIA. The Global Race to 5G; CTIA: Washington, DC, USA, 2018.

19. IEEE. IEEE 802.1 Working Group March 10-15, 2019 Plenary Session Vancouver, BC, Canada. Available online: https://1.ieee802.org/march-2019-plenary-meeting-in-vancouver-bc-canada/ (accessed on 4 November 2019).

20. Capellari, S.; De Stefano, D. Academic inventors, allocation of patent rights and knowledge diffusion: Subnetwork structures in university-owned and universityinvented patents in two Italian universities. Sci. Public Policy 2016, 43, 585-593. [CrossRef]

21. Chen, Z.; Guan, J. The core-peripheral structure of international knowledge flows: Evidence from patent citation data. $R$ D Manag. 2016, 46, 62-79. [CrossRef]

22. Sonmez, Z. Inventor mobility and the geography of knowledge flows: Evidence from the US biopharmaceutical industry. Sci. Public Policy 2017, 44, 670-682. [CrossRef]

23. Huenteler, J.; Ossenbrink, J.; Schmidt, T.S.; Hoffmann, V.H. How a product's design hierarchy shapes the evolution of technological knowledge-evidence from patent-citation networks in wind power. Res. Policy 2016, 45, 1195-1217. [CrossRef]

24. Yoon, J.; Park, Y.; Kim, M.; Lee, J.; Lee, D. Tracing evolving trends in printed electronics using patent information. J. Nanoparticle Res. 2014, 16,1-15. [CrossRef]

25. De Prato, G.; Nepelski, D. Global technological collaboration network: Network analysis of international co-inventions. J. Technol. Transf. 2014, 39, 358-375. [CrossRef]

26. Fonseca, B.P.F.; Fernandes, E.; Fonseca, M.V.A. Collaboration in science and technology organizations of the public sector: A network perspective. Sci. Public Policy 2017, 44, 37-49. [CrossRef]

27. Park, I.; Jeong, Y.; Yoon, B.; Mortara, L. Exploring potential R\&D collaboration partners through patent analysis based on bibliographic coupling and latent semantic analysis. Technol. Anal. Strateg. Manag. 2015, 27, 759-781.

28. Zahringer, K.; Kolympiris, C.; Kalaitzandonakes, N. Time to patent at the USPTO: The case of emerging entrepreneurial firms. J. Technol. Transf. 2018, 43, 923-952. [CrossRef]

29. Lee, W.J.; Lee, W.K.; Sohn, S.Y. Patent network analysis and quadratic assignment procedures to identify the convergence of robot technologies. PLoS ONE 2016, 11, e0165091. [CrossRef] [PubMed]

30. Weng, C.S. Structural embeddedness and position: Evidences from affiliation of patent with technological classifications. Technol. Anal. Strateg. Manag. 2018, 30, 1148-1165. [CrossRef]

31. Borgatti, S.P. Identifying sets of key players in a social network. Comput. Math. Organ. Theory 2006, 12, 21-34. [CrossRef]

32. Bass, S.D.; Kurgan, L.A. Discovery of factors influencing patent value based on machine learning in patents in the field of nanotechnology. Scientometrics 2010, 82, 217-241. [CrossRef]

33. Ko, S.S.; Ko, N.; Kim, D.; Park, H.; Yoon, J. Analyzing technology impact networks for R\&D planning using patents: Combined application of network approaches. Scientometrics 2014, 101, 917-936. 
34. Hao, J.; Yan, Y.; Gong, L.; Wang, G.; Lin, J. Knowledge map-based method for domain knowledge browsing. Decis. Support Syst. 2013, 61, 106-114. [CrossRef]

35. Kim, Y.; Jang, S.N. Mapping the knowledge structure of frailty in journal articles by text network analysis. PLoS ONE 2018, 13, e0196104. [CrossRef] [PubMed]

36. Ireni-Saban, L.; Borohowitch, E. Brokers and entrepreneurs in human stem cell governance networks in the United States. Rev. Policy Res. 2017, 5, 660-681. [CrossRef]

37. Walsh, J.N. Developing new categories of knowledge acquisition, translation and dissemination by technological gatekeepers. Int. J. Inf. Manag. 2015, 35, 594-605. [CrossRef]

38. Choe, H.; Lee, D. The structure and change of the research collaboration network in Korea (2000-2011): Network analysis of joint patents. Scientometrics 2017, 111, 917-939. [CrossRef]

39. García Muñiz, A.S.; Cuervo, M.R.V. Exploring research networks in Information and Communication Technologies for energy efficiency: An empirical analysis of the 7th Framework Programme. J. Clean. Prod. 2018, 198, 1133-1143. [CrossRef]

40. Ericsson. The 5G Business Potential; Ericsson: Stockholm, Sweden, 2017.

41. Eghbal, M.K.; Shadaram, M. Expandable high-capacity wavelength division multiplex-over-optical code division multiple access millimeter wave radio-over-fiber system. Opt. Eng. 2019, 58, 1-9. [CrossRef]

(C) 2019 by the author. Licensee MDPI, Basel, Switzerland. This article is an open access article distributed under the terms and conditions of the Creative Commons Attribution (CC BY) license (http://creativecommons.org/licenses/by/4.0/). 